\title{
Computational methods of Gaussian Particle Swarm Optimization (GPSO) and Lagrange Multiplier on economic dispatch issues (case study on electrical system of Java-Bali IV area)
}

\author{
S. Komsiyah, \\ Bina Nusantara University, Kebon Jeruk, West Jakarta, Indonesia.
}

\begin{abstract}
The objective in this paper is about economic dispatch problem of electric power generation where scheduling the committed generating units outputs so as to meet the required load demand at minimum operating cost, while satisfying all units and system equality and inequality constraint. In the operating of electric power system, an economic planning problem is one of variables that its must be considered since economically planning will give more efficiency in operational cost. In this paper the economic dispatch problem which has non linear cost function solved by using swarm intelligent method is Gaussian Particle Swarm Optimization (GPSO) and Lagrange Multiplier. GPSO is a population-based stochastic algorithms which their moving inspired by swarm intelligent and probabilities theories. To analize its accuracy, the economic dispatch solution by GPSO method will be compared with Lagrange multiplier method. From the running test result the GPSO method give economically planning calculation which it better than Lagrange multiplier method and the GPSO method faster to getting error convergence. Therefore the GPSO method have better performance to getting global best solution than the Lagrange method.
\end{abstract}

\section{Introduction}

The problem in this paper is the economic power dispatching, optimization of power distribution operations at generating unit with a certain load that economic calculation is a priority or value that must be taken into account to take advantage of the capital infested. The efficiency of use an optimal fuel will reduce production costs for electric power distributor companies. In the operation of the power system is always done on a load sharing power unit that will supply the load, it is related to the process of minimizing the cost of production of electric power and power loss in the transmission line is missing. However, in this study a total loss of power on transmission lines is not taken to account.

A power system is generally divided into three parts, namely power generation, power transmission and power dispatching. In power system, the generation of thermal energy (based on different technologies such as the burning of coal, nuclear, gas combined cycle, gas turbine) and hydro power will be distributed to various generating stations through high voltage transmission line [6]. Therefore, before ending at the consumer, electrical energy is converted into a lower voltage level and distributed to homes, municipalities, shopping malls, factories and so on through the distribution network of electrical energy and generating station [13]. In economic dispatch problem, the mathematical optimization in power system operation that aims to determine the best setting power generation or optimal number of generating units so as to meet the needs of the load on the system with minimum production cost [4].

In calculating the economic dispatch problem has been widely used conventional approaches such as the method Gradient, Lambda Iteration method, Newton's method, the algorithm Linear Programming, Dynamic Programming algorithm, etc. [13]. Conventional methods to find good solutions in a fast time but with the selection of initial starting value (lambda) is not easy, and less efficient, and the method can only be applied to simple problems on a small scale. Heuristic optimization method has also been widely applied to solve economic dispatch problems such as Genetic Algorithm (GA) [5], Tabu Search (TS) [7], Evolutionary Programming (EP) [1], Ant Colony Optimization (ACO) [10], and Particle Swarm Optimization (PSO) [8],[9],[11],[14]. The method of neural networks that have been used such as Simulated Annealing (SA) [12], and the Hopfield network (HN) [3]). The method can be used for complex problems, but still produced a slower rate of convergence to approximate the optimal solution. Therefore, improvement is still needed to get a better solution. From this paper will be compared the method of Lagrange 
Multiplier and Gaussian Particle Swarm Optimization (GPSO) in finding a solution of economic dispatch problem and then compared of performed their analysis result.

\section{Characteristics of incremental heat rate and incremental fuel cost}

Some of the characteristics of plants is characteristic of the incremental heat rate and incremental fuel cost characteristics. These characteristics indicate the amount of increase in energy input or fuel prices by any change output in MegaWatt of the generating unit. Characteristic curve of the incremental heat rate or the incremental fuel cost can be seen in figure 1 . While equation incremental heat rate and incremental fuel cost equation can be seen in equation (1) to (4).

Incremental heat rate formula is

$$
\frac{\Delta H}{\Delta P}\left(\frac{\text { Mkal }}{\text { MWhour }}\right)
$$

Incremental fuel cost formula is:

$$
\frac{\Delta F}{\Delta P}\left(\frac{\text { Rupiah }}{\text { MWhour }}\right)
$$

If the $\Delta$ value is very small then the above equation can be expressed as follows:

Incremental heat rate :

$$
\frac{d H}{d P}\left(\frac{\text { Mkal }}{\text { MWhour }}\right)
$$

and incremental fuel cost formula

$$
\frac{d F}{d P}\left(\frac{\text { Rupiah }}{\text { Mwhour }}\right)
$$

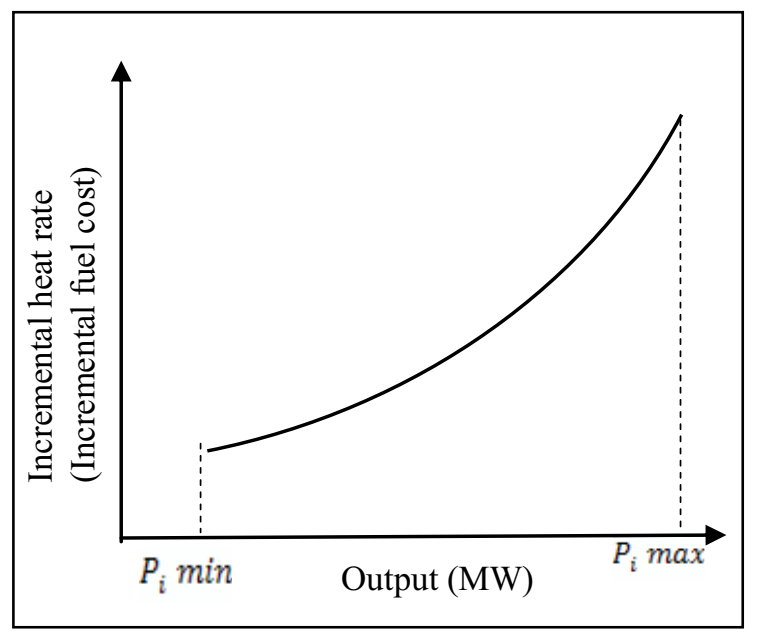

Fig. 1. Curve of characteristic incremental heat rate (incremental fuel cost)

\section{Economic dispatch model}

Objective function from economic dispatch issues as in equation (5)

$$
f T=\sum_{i=1}^{N} F_{i}\left(P_{i}\right)
$$

with equation (6) are nonlinear equation

$$
F_{i}\left(P_{i}\right)=a_{i}+b_{i} P_{i}+c_{i} P_{i}^{2}
$$

And

fT $=$ total generating cost (Rupiah/hour).

$F_{i}\left(P_{i}\right) \quad=$ input output cost function thermal generator i (Rupiah/hour)

$P_{i} \quad=$ Output thermal generator i (MW)

$N \quad=$ number of operated generator

$i=$ indeks from number of operated generator

$a_{i}, b_{i}, c_{i}=$ coefisien of fuel cost thermal generator $i$.

Dimension from coefisien $a_{i}, b_{i}, c_{i}$ respectively is Rupiah/hour, Rupiah/MW.hour, and Rupiah/MW' hour [2],[6],[13].

Equation (7) is constraints equation from this problem .

$$
\sum_{i=1}^{N} P_{i}=P_{D}
$$

Where $P_{D}=$ total power form demand system $(\mathrm{MW})$

$$
P_{i} \quad=\text { output power of generator } i(\mathrm{MW})
$$

Inequality constraints that must be met on equation (8).

$$
P_{i \min } \leq P_{i} \leq P_{i \max }
$$

$P_{i \min }$ and $P_{i \max }$ are respectively to output power minimum and maximum limit from generator $i$.

\section{Step solution for Lagrange Multiplier Method}

Lagrange multiplier method is the conventional method to determine the Lagrange equation between the objective function and the constraints. The formulation of Lagrangian Multiplier for economic dispatch can be seen in equation (9).

$$
F=F_{T}+\lambda\left(P_{D}-\sum_{i=1}^{n} P_{i}\right)
$$

Where $\lambda$ is the Lagrangian Multiplier. Differentiating $\mathrm{F}$ with respect to the generation $P_{i}$ and equating to zero gives the condition for optimal operation of the system such as equation (10). 


$$
\frac{\partial F}{\partial p_{i}}=\frac{\partial F_{T}}{\partial p_{i}}-\lambda=0
$$

Since $\quad F_{T}=F_{1}+F_{2}+F_{3}+\cdots+F_{n}$ and $P_{i}=P_{1}+P_{2}+P_{3}+\cdots+P_{n}$ so that from equation (10) can be modified as in equation (11)

$$
\frac{\partial F_{T}}{\partial P_{i}}=\frac{d F n}{d P n}=\lambda=2 c_{i} P_{i}+b_{i}
$$

therefore the condition for optimum operation can be meet when the each of generators have the same incremental cost $(\lambda)$, that can be seen in equation (12).

$$
\frac{d F_{1}}{d P_{1}}=\frac{d F_{2}}{d P_{2}}=\frac{d F_{3}}{d P_{3}}=\cdots=\frac{d F_{n}}{d P_{n}}=\lambda
$$

The iterations of Lagrange are first, we choose by trial to selecting the $\lambda_{1}$, then compute the value of $P_{1}, P_{2}, P_{3}, \ldots P_{N}$ with the formula in equation (11) and the total sum of $P_{1}, P_{2}, P_{3}, \ldots P_{N}$. Next evaluate the constraint equation value that is difference from generated power total and the total load. If the amount of error to meet the specified tolerance, then it is the solution as finish step. But if do not meet the tolerance, we have to back to the first step to reselecting the $\lambda$ value.

These stages are clearly the method of Lagrange multipliers as shown in figure 2 [6].

Algorithm of Lagrange Multiplier method are clearly as follow :

1. Read of data. Data that must be considered is the amount of load required, the equation incremental cost, and minimum power limits the maximum power limit to be raised.

2. Initialization of parameter values

Initial value parameter $\lambda_{1}$ selected and determined it by trial and error.

3. Count value of $P_{1}, P_{2}, P_{3}, \ldots P_{N}$

4. Count of generating total power $\left(\sum_{i=1}^{N} P_{i}\right)$

5. Evaluation of constraint equation values that is difference from generated power total and the total load. if the amount of error to meet specified tolerances (0.0001), then towards the step 6. If you do not meet the tolerances back to step 2 .

6. Find the solution $P_{1}, P_{2}, P_{3}, \ldots P_{N}$.

7. Finish step.

\section{Step Solution for Gaussian Particle Swarm Optimization (GPSO)}

PSO method used in this study is a combined PSO with Gaussian probability distribution function (GPSO) used to random generated numbers. Gaussian distribution can provide faster convergence in local search. Gaussian distribution is used to generate random numbers in the interval $[-1,1]$ on the acceleration coefficient cognitive part, acceleration coefficient social part and the individual's initial position and initial velocity. The variables used and the integer value is dynamic inertia weight in a linear equation. GPSO stages are clearly shown in figure 3 .

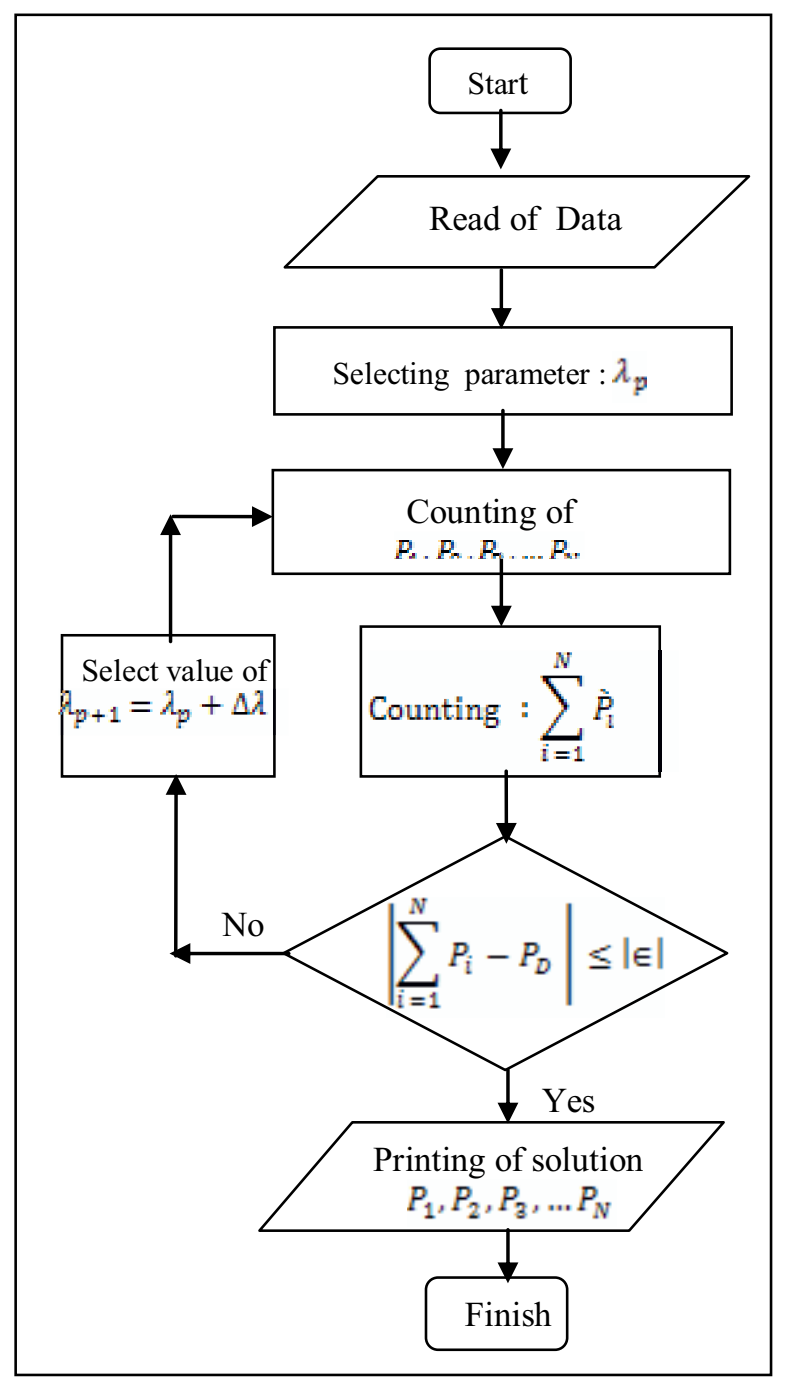

Fig 2. Flowchart of Lagrange Multiplier methods

Procedure of implementation GPSO method :

Step 1. Initialization

Initialize swarm (population) of particles with random positions and velocities in the $n$-dimensional space using a probability function distributed problem Gaussian.

\section{Step 2. Evaluate}

Evaluate objective function from particle in the swarm (population)

\section{Step 3. First comparison}

Compare each particle by particle pbest of objective function. If the current value is better than pbest, then set pbest value equal to the current value and the pbest location equal to the current location in n-dimensional space. 
Step 4. Second Comparison

Compare the value of objective function with the population as a whole before reaching the best. If the current value is better than gbest, then gbest to change the index values and ranks of the particles present.

Step 5. Update

Update for velocity and particle position. 3 .

Step 6. Stop condition

Return to step 2 until stopping criteria are met, a sufficient condition is usually the best objective function value or the maximum number of iterations.

4.

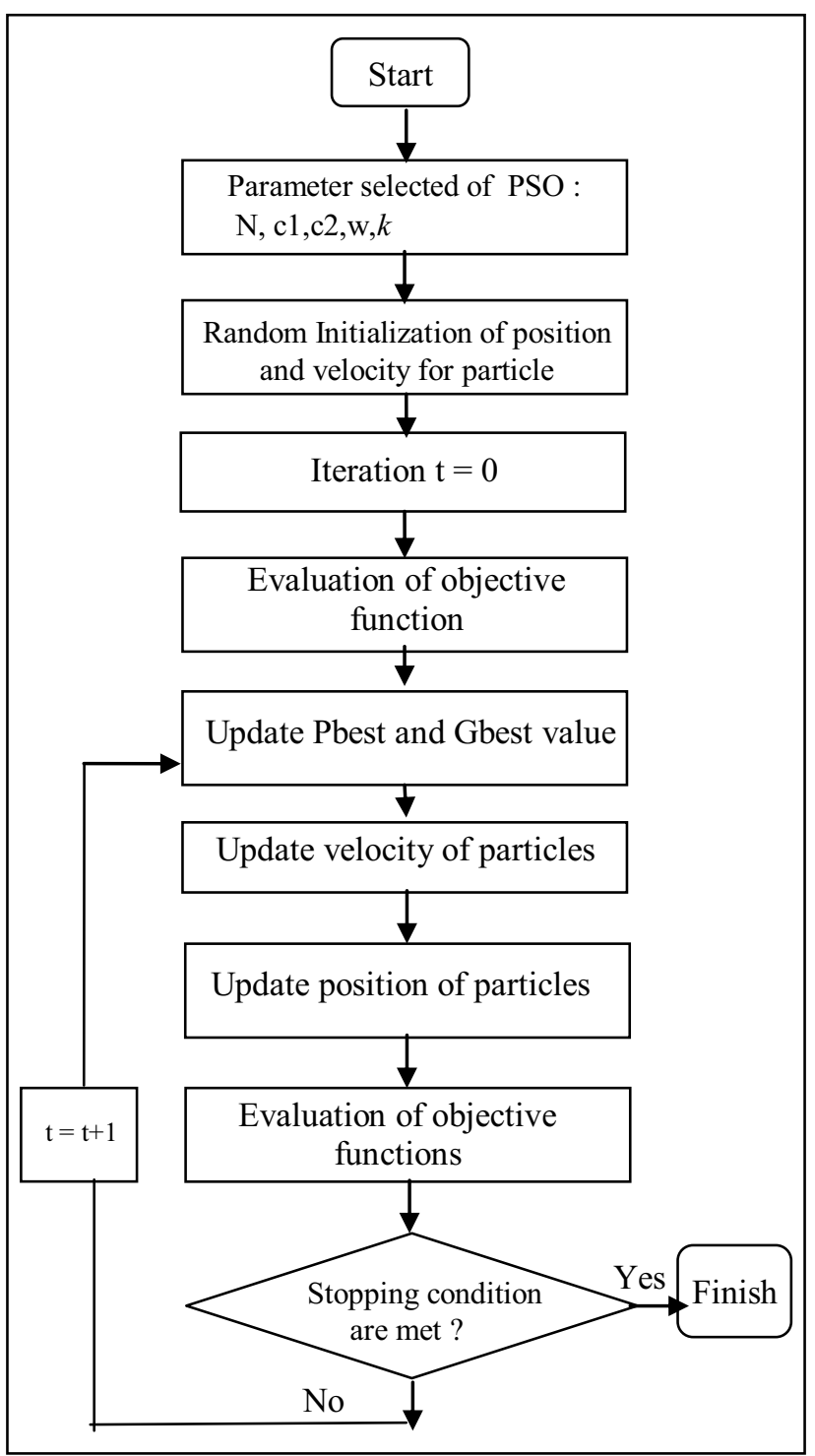

Fig 3. Flow chart of GPSO method

The mathematic equation model in GPSO method can be seen in equation (13) to (19) below.

1. Initialization of particle position :

$$
X_{i}^{0}=\left(P_{i}^{0}, \ldots, P_{i}^{0}\right)
$$

2. Initialization of particle velocity :

$$
V_{i}^{0}=\left(V_{i 1}^{0}, \ldots . V_{i n}^{0}\right)
$$

3. Adjusment of prior particle velocity

$$
-k\left(\left(P_{i j} \max -P_{i j \min }\right) \leq V_{i j}^{0} \leq k\left(\left(P_{i j} \max -P_{i j} \min \right)\right.\right.
$$

4. Update velocity of particle

$V_{i}^{k+1}=w V_{i}^{k}+c_{1}$ randg $_{1^{\prime}}\left(\right.$ Pbest $\left._{i}^{k}-X_{i}^{k}\right)+c_{2}$ rand $G_{2}\left(\right.$ Gbost $\left.^{k}-X_{i}^{k}\right)$

5. Inertia weight

$$
w=w_{\max }-\frac{w_{\max }-w_{\min }}{\text { Iter }_{\max }} x \text { Iter }
$$

6. Update position of particle

$$
X_{i}^{k+1}=X_{i}^{k}
$$

.7. Update Pbest and Gbest

$$
\text { Pbest }{ }_{i}^{k+1}=\left\{\begin{array}{cl}
X_{i}^{k+1}, & \text { if } T C_{i}^{k+1}<T C_{i}^{k} \\
\text { Pbesti }, & \text { if else }
\end{array}\right.
$$

Where :

$V_{i}^{k}=$ particle velocity (change output of generator) $i$ at iteration $k$

$P_{i}^{h} \quad=$ Particle of individual (output of generator) $\mathrm{i}$ at iteration $\mathrm{k}$

$w=$ parameter of inertia weight

$c_{1}, c_{2}=$ coeffisien of acceleration

$\operatorname{rand} g_{1}, \operatorname{rand} G_{2}=$ random number with Gaussian distribution on $[-1,1]$

$X_{i}^{k}=$ position of individual (output of generator) $i$ at iteration $k$

Pbest $_{i}^{k}=$ the best positionof individual (personal best from output generator) $i$ at iteration $k$

Gbest $^{k}=$ the best position of swarm (global best from output generator) $\mathrm{i}$ at iteration $k$

$w_{\min }, w_{\max }=$ prior and final of inertia weight

Iter $=$ iteration number at the time 
Iter $_{\max }=$ maximum of iteration number

$\mathrm{k}=$ transition vector on $[0.01,0.1]$

$P_{i j, \min }=$ minimum limit of output generator $i$ at

element $\mathrm{j}$ th

$P_{i j, \max }=$ maximum limit of output generator I at element $\mathrm{j}$ th

$T C_{i}^{h}=$ total cost (objective function) individual $i$ at iteration $k$

\section{Simulation Result}

The results of calculation fuel cost for each plant by the Lagrange multipliers and the Gaussian Particle Swarm Optimization methods is described in table 1 below.

Table 1. Comparison of economic dispatch solution with Lagrange Multiplier and GPSO method

\begin{tabular}{|c|c|c|c|c|c|}
\hline \multirow[b]{2}{*}{ No } & \multirow[b]{2}{*}{ Name of generator } & \multicolumn{2}{|c|}{ Lagrange Multiplier Method } & \multicolumn{2}{|r|}{ GPSO method } \\
\hline & & $\begin{array}{l}\text { Load dispatch } \\
\text { (MW) }\end{array}$ & $\begin{array}{l}\text { Generating cost } \\
\text { (Rupiah / hour) }\end{array}$ & $\begin{array}{l}\text { Load } \\
\text { dispatch } \\
(\mathrm{MW})\end{array}$ & $\begin{array}{l}\text { Generating cost } \\
\text { (Rupiah / hour) }\end{array}$ \\
\hline 1 & PLTU Perak 3-4 & 150,0000 & $14.181 .123,7500$ & 149,9999 & $14.181 .123,6649$ \\
\hline 2 & PLTU Gresik 3-4 & 208,8174017 & $49.541 .798,5634$ & 216,1062 & $51.586 .517,8414$ \\
\hline 3 & PLTU Paiton 1-2 & 420,6049915 & $86.454 .869,1877$ & 430,4288 & $89.200 .118,1974$ \\
\hline 4 & PLTG Gilimanuk & 145,0000 & $20.138 .519,0000$ & 145 & $20.138 .519,6$ \\
\hline 5 & PLTG Pesanggaran & 15,0000 & $14.119 .296,2400$ & 15,0000 & $14.119 .296,2400$ \\
\hline 6 & PLTD Pesanggaran & 75,0000 & $17.005 .228,4400$ & 75,0000 & $17.005 .228,4400$ \\
\hline 7 & PLTGU Gresik & 799,141194 & $156.461 .390,1196$ & 782,065 & $151.613 .208,5275$ \\
\hline \multirow[t]{2}{*}{8} & PLTGU Grati & $1.052,00$ & $233.844 .409,1200$ & $1.052,00$ & $233.844 .409,1200$ \\
\hline & \multicolumn{2}{|c|}{ Total $=\mathbf{2 8 6 5 , 5 6 3 6}$} & 591.746.634,4207 & $2.865,60$ & $591.688 .421,6313$ \\
\hline
\end{tabular}

Comparison the results of the convergence error by Lagrange multipliers and GPSO on the calculation of economic dispatch of electric power generation system of Java-Bali IV area as seen in table 2 with total load dispatch 2865.6 MW according to table A2.

Table 2. The results of the convergence errors

\begin{tabular}{|c|c|c|c|}
\hline Methods & $\begin{array}{c}\text { Error } \\
\text { dispatch } \\
\text { (MW) }\end{array}$ & $\begin{array}{c}\text { Objective function } \\
\text { (Rupiah/hour) }\end{array}$ & $\begin{array}{c}\text { Cpu running } \\
\text { time (seconds) }\end{array}$ \\
\hline $\begin{array}{c}\text { Lagrange } \\
\text { Multiplier }\end{array}$ & 0.0364 & $591.746 .634,4207$ & 373,930709 \\
\hline GPSO & 0 & $591.688 .421,6313$ & 112,823027 \\
\hline
\end{tabular}

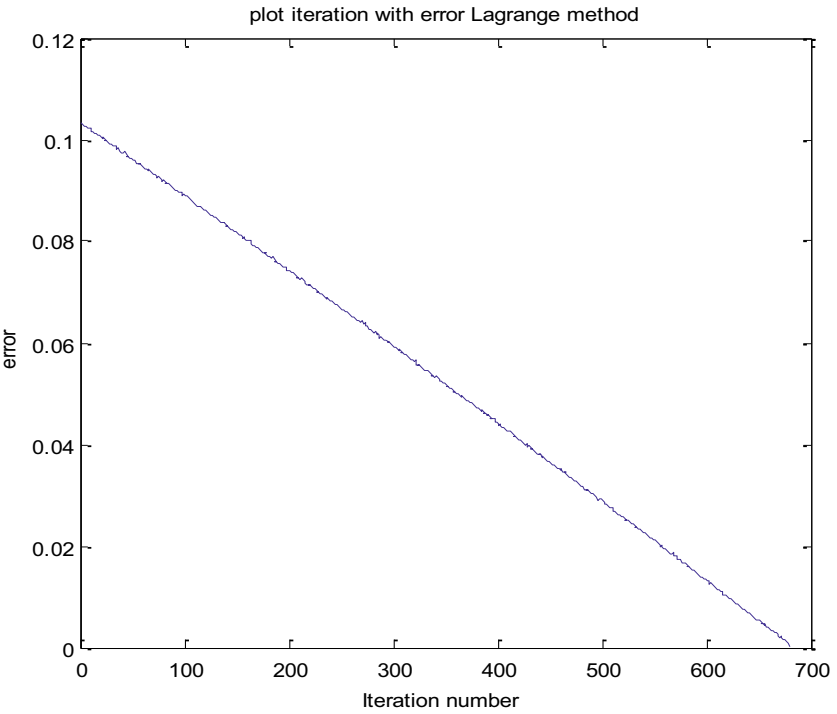

Fig 4. Error convergence plot of Lagrange method
The error convergence plot of both methods can be seen in figure 4 and figure 5 . This figure describe that GPSO method have better performance to getting global best solution than Lagrange method.

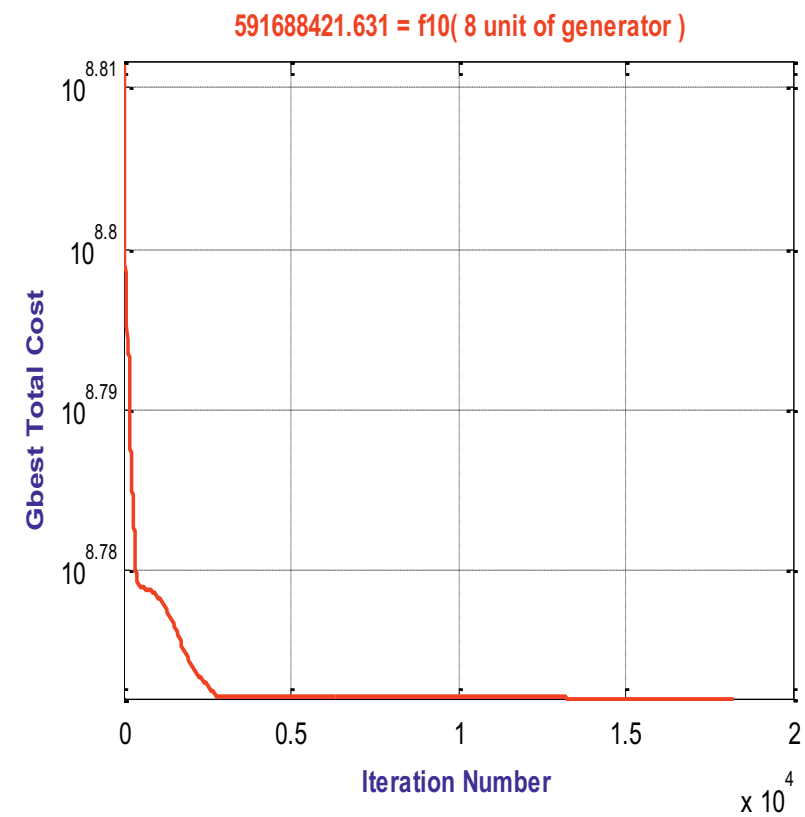

Fig 5. Error convergence plot of GPSO method

Comparison result of the output generators from PLN corporation (state electricity company), Lagrange multiplier and GPSO methods can be illustrated in the graphic in Figure 6 below. 


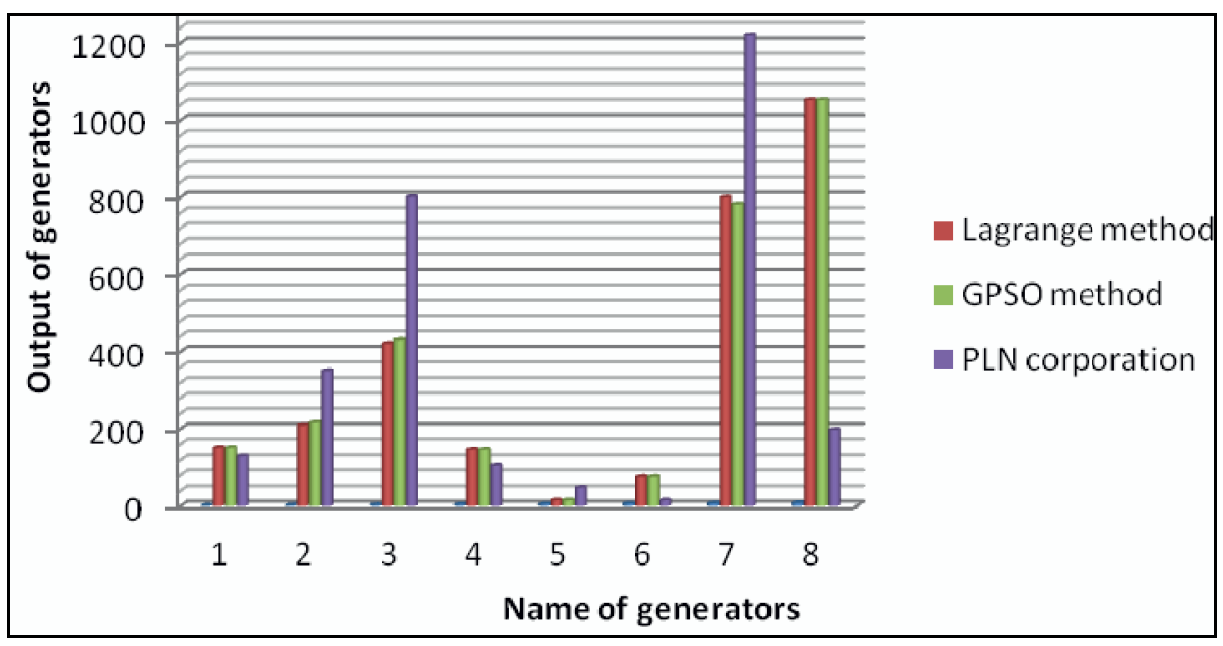

Fig 6. Comparison result of output generators

\section{Analysis Result}

Analysis of simulation results based on the solution obtained from the two methods on case studies of power system Java-Bali IV area where GPSO method which is a combination of heuristic techniques with Gaussian distributed random numbers were able to get a better solution than the method of Lagrange Multiplier from some testing or running this program. GPSO method faster search the local minimum and better in getting error convergence than the Lagrange multiplier method. The Lagrange multiplier method need running time much to get error convergence than the GPSO method. Calculation of economic dispatch using GPSO method gives different convergence acceleration due to random results for the initial position of a particle or individual is different, resulting in different global best that can affect the acceleration of convergence.

The economic dispatch problem, in this case for data generation power systems Java-Bali IV area, the calculation results obtained by the method of Lagrange multipliers compared to the data of real systems PLN corporation (state electricity company) more optimum generating cost savings 55.868.632.0793 rupiahs per hour (efficiency of fuel cost about $9.44 \%$ per hour). Optimum levels of the generation cost savings between the GPSO method and PLN corporation (state electricity company) is $55.926 .844,8687$ rupiah per hour (efficiency of fuel cost about $9.45 \%$ per hour). While the optimum levels of the generation cost savings compared to Lagrange Multiplier and GPSO methods is 58.212,7894 rupiahs per hour (efficiency of fuel cost about $0.0098 \%$ per hour).

\section{Discussion}

The prospects for the development of this research can be used as a future research study are as follows: 1. Gaussian Particle Swarm Optimization (GPSO) method used in this study still requires further research and development and can also be combined with other methods to further improve its performance. 2. Economic dispatch problems in this study can be extended to counting losses in power transmission, engine repairs and maintenance costs. Besides the objective function minimizes the total cost of fuel can be combined with the objective function to minimize pollutant emissions from the generation process.

\section{References}

1. A.M.A Aziz, J.I Musirin, T.K.A Rahman, First Int. PEConf, 144 (2006)

2. L.S Coelho and C.S Lee, J. of Electrical Power and Energy Systems 30297 (2008)

3. V.N Dieu, W. Ongsakul, International Symposium on Electrical and Electronics Engineering 219 (2007)

4. A.A.A El-Ela, R.A.A El-Sehiemy, WSEAS Transactions on Power Systems 2 225(2007)

5. A. Laoufi, A. Hazzab, M.Rahli, Inter J. of Appl Engineering 1409 (2007)

6. D. Marsudi Operation System of electrical power (Graha Ilmu, Yogyakarta, Indonesia) (2006)

7. W. Ongsakul, S. Dechanupaprittha, I. Ngamroo IEEE Proceeding of Generation, Transmission and Distribution, 151157 (2004)

8. B.K Panigrahi, S. Das , J. of Energy Conversion and Management, 491407 (2008)

9. J.B Park, J.R Shin, J.W Jeong, Interl J. of Innovation in Energy System and Power 1 (2006)

10. L.Slimani L, T. Bouktir, Inter J of Computational Intelligence Paper 3145 (2007)

11. A.Y Wahyono, Economic Dispatch with optimization to active and reactive power, Final 
Project, Institut Teknologi Sepuluh Nopember Surabaya, (2000)

12. K.P Wong, C.C Chung, IEEE Proceeding of Generation, Transmission and Distribution 140509 (1999)

13. A.J Wood, B.F Wollenberg, Power Generation, Operation And Control, $2^{\text {nd }}$ edition, (John Wiley \& Sons, Inc, New York). (1999)

14. B. Zhao, Y.J Cao, J. of Zhejiang University SCIENCE 6420 (2005).

\section{Appendices}

Data from PLN corporation (State Electricity Company) Java-Bali IV Area ,1999 can be seen in Table A1 and A2. While the design of graphical user interface from both of methods can be seen in Table A3 and A4 below.

Table A1. Data of equation of generating cost on electrical system Java-Bali IV area.

\begin{tabular}{|cll|}
\hline No. & Nama of Generators & \multicolumn{1}{c|}{ Generating cost equation } \\
\hline 1 & PLTU Perak 3-4 & $\mathrm{F}=3.05 P^{2}+89780.85 P+645371.25$ \\
\hline 2 & PLTU Gresik 3-4 & $\mathrm{F}=200.78 P^{2}+195212.5 P+23078.4$ \\
\hline 3 & PLTU Paiton 1-2 & $\mathrm{F}=263 P^{2}+55627.6 P+16530671.97$ \\
\hline 4 & PLTG Gilimanuk & $\mathrm{F}=81.38 P^{2}+92284.7 P+5046223.6$ \\
\hline 5 & PLTG Pesanggaran & $\mathrm{F}=6573.62 P^{2}+305711.06 P+8054565.84$ \\
\hline 6 & PLTD Pesanggaran & $\mathrm{F}=825.3 P^{2}+96382.38 P+5134237.44$ \\
\hline 7 & PLTGU Gresik & $\mathrm{F}=112.8 P^{2}+105555 P+70955.5$ \\
\hline 8 & PLTGU Grati & $\mathrm{F}=28.85 P^{2}+178376.8 P+14263605.12$ \\
\hline
\end{tabular}

Table A2. Data of total load dispatch or output operated generator with its generating Cost on electrical system Java-Bali IV area.

\begin{tabular}{|r|l|r|r|r|r|}
\hline No. & Name of Generators & $\begin{array}{l}\text { Minimum } \\
\text { load limit }\end{array}$ & $\begin{array}{l}\text { Maximum } \\
\text { load limit }\end{array}$ & $\begin{array}{c}\text { Total Load } \\
\text { dispatch } \\
\text { (MW) }\end{array}$ & $\begin{array}{c}\text { Generating cost } \\
\text { (Rupiah/hour) }\end{array}$ \\
\hline 1 & PLTU Perak 3-4 & 25,00 & 150,00 & 130 & $35.859 .136,80$ \\
\hline 2 & PLTU Gresik 3-4 & 100,00 & 400,00 & 350 & $92.943 .003,40$ \\
\hline 3 & PLTU Paiton 1-2 & 225,00 & 800,00 & 801 & $140.714 .027,40$ \\
\hline 4 & PLTG Gilimanuk & 85,00 & 145,00 & 105 & $15.633 .331,60$ \\
\hline 5 & PLTG Pesanggaran & 15,00 & 50,00 & 47,8 & $8.461 .247,09$ \\
\hline 6 & PLTD Pesanggaran & 10,00 & 75,00 & 14.8 & $6.741 .470,37$ \\
\hline 7 & PLTGU Gresik & 263,00 & $1.578,00$ & 1220 & $296.739 .575,50$ \\
\hline 8 & PLTGU Grati & 263,00 & $1.052,00$ & 197 & $50.523 .474,37$ \\
\hline & Total & & & $\mathbf{2 8 6 5 , 6}$ & $\mathbf{6 4 7 . 6 1 5 . 2 6 6 , 5 0}$ \\
\hline
\end{tabular}


Table A3. Design of Graphical User Interface of GPSO method

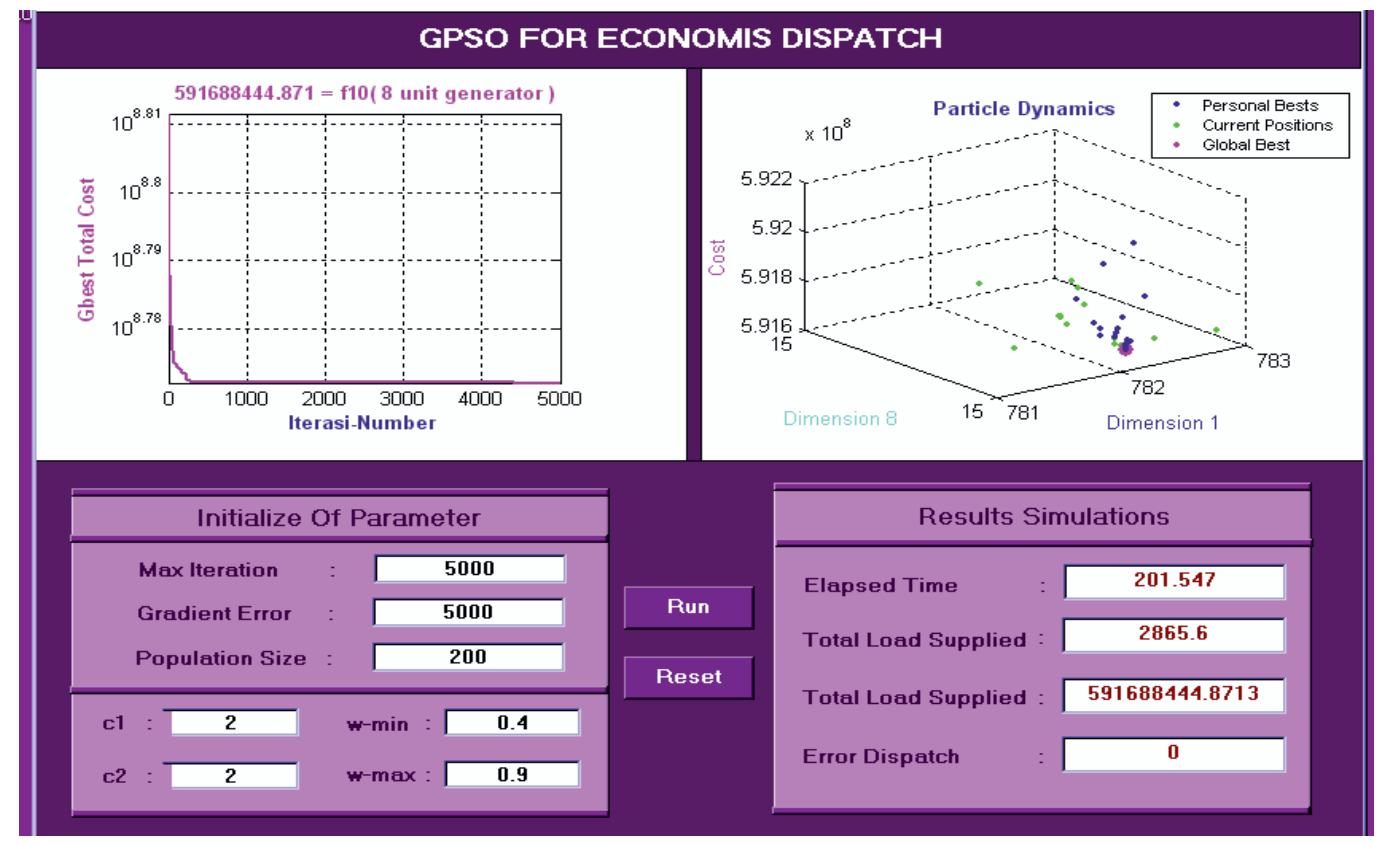

Table A4. Design of Graphical User Interface of Lagrange Multiplier method

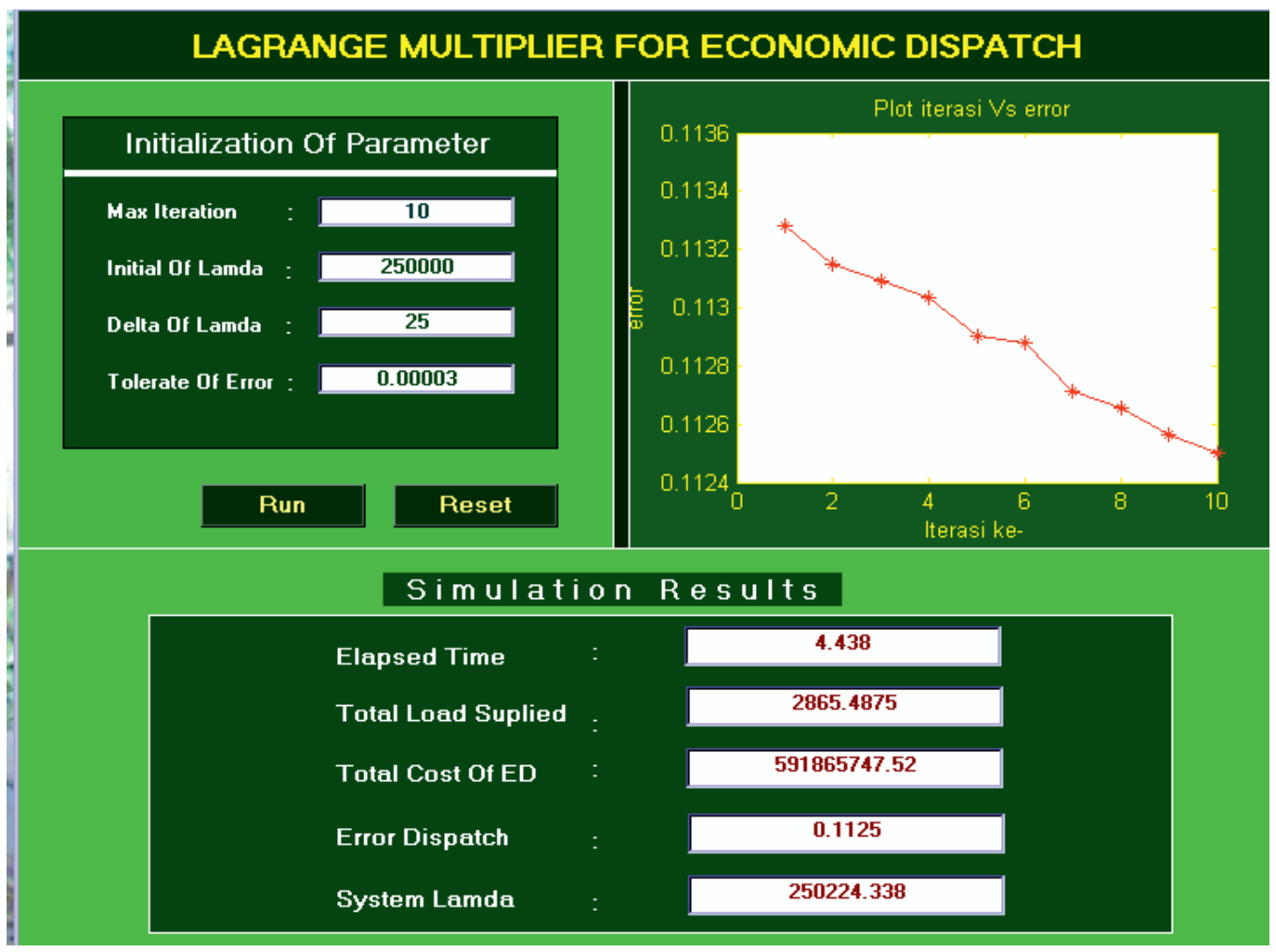

